\title{
ZICOSUL E A PARADIPLOMACIA NAS FRONTEIRAS DA AMÉRICA DO SUL
}

\author{
ZICOSUL AND THE PARADIPLOMACY AT SOUTH AMERICAN \\ BORDERS
}

\section{ZICOSUR Y PARADIPLOMACIA EN LAS FRONTERAS DE SUDAMÉRICA}

\author{
Fabio Roberto Cordeiro da SILVA ${ }^{1}$ \\ Alexandre Bergamin VIEIRA ${ }^{2}$ \\ Kamila Madureira da SILVA ${ }^{3}$ \\ Camilo Pereira CARNEIRO ${ }^{4}$
}

\begin{abstract}
Resumo: Criada em 1997, a ZICOSUL (Zona de Integração do Centro-Oeste da América do Sul) constitui uma iniciativa em prol do desenvolvimento regional do subcontinente sul-americano. Composta por governos regionais dos países da região, no Brasil cinco estados fazem parte da Organização. Passadas duas décadas do início da iniciativa a mesma é muito pouco conhecida e difundida na mídia. Nesse sentido, o presente artigo tem o objetivo de analisar a ZICOSUL no âmbito da paradiplomacia em zonas de fronteira do Centro Oeste da América do Sul, área chave para a integração regional do subcontinente. $\mathrm{O}$ artigo traz ainda uma análise da paradiplomacia desenvolvida no estado de Mato Grosso do Sul. Trata-se de uma pesquisa qualitativa, pautada em análise bibliográfica e documental, sob a ótica das Relações Internacionais e do Desenvolvimento Regional, enriquecida com cartografia temática elaborada pelos autores.
\end{abstract}

Palavras-chave: ZICOSUL. América do Sul. Fronteiras. Paradiplomacia. Mato Grosso do Sul

\begin{abstract}
Created in 1997, ZICOSUR (Midwest Integration Zone of South America) is an initiative for the regional development of South America. Formed by subnational entities from the countries of the region, in Brazil five states are part of the Organization. Two decades after the begining of the initiative it is very unknown and little widespread in the media. In this sense, this article aims to analyze the impacts of ZICOSUR and the paradiplomacy in border areas of South America central west region, a important area to regional integration in the continent. Finally brings an analysis of paradiplomacy initiatives in Mato Grosso do Sul state. This paper is a qualitative research, based on bibliographic and documentary analysis, from the perspective of International Relations and Regional Development, enriched with thematic cartography elaborated by the authors.
\end{abstract}

Keywords: ZICOSUR. South America. Borders. Paradiplomacy. Mato Grosso do Sul.

Resumen: Creado en 1997, ZICOSUR (Zona de Integración del Centro Oeste de América del Sur) es una iniciativa para el desarrollo regional de América del Sur. Formado por entidades subnacionales de los países de la región, en Brasil cinco estados son parte de la Organización. Dos décadas después de su inicio, ZICOSUR es muy desconocido y poco difundido en los medios de comunicación. En este sentido, este artículo tiene como objetivo analizar los impactos de ZICOSUR y de la paradiplomacia en las zonas fronterizas de la región centro oeste de América del Sur, un área importante para la

\footnotetext{
1 Bacharel em Direito. Discente do Mestrado em Fronteiras e Direitos Humanos da UFGD. E-mail: frcordeiroadv@gmail.com.

${ }^{2}$ Doutor em Geografia. Professor do Curso de Geografia da UFGD. E-mail: alexandrevieira@ufgd.edu.br.

${ }^{3}$ Licenciada em Geografia. Discente do Mestrado em Geografia da UFGD. E-mail: kamila_agro@ hotmail.com.

4 Doutor em Geografia. Professor do Mestrado em Fronteiras e Direitos Humanos da UFGD. E-mail: pereiracarneiro.camilo@gmail.com.
} 
integración regional en el continente. Por fin, el artículo presenta un análisis de iniciativas de paradiplomacia en el estado de Mato Grosso do Sul. Este trabajo es una investigación cualitativa, basada en análisis bibliográfico y documental, desde la perspectiva de las Relaciones internacionales y del Desarrollo Regional, enriquecida con cartografía temática elaborada por los autores.

Palabras clave: ZICOSUR. Sudamerica. Fronteras. Paradiplomacia. Mato Grosso do Sul.

\section{Introdução}

O presente trabalho tem como intuito analisar a prática da paradiplomacia nas relações internacionais por meio da atuação dos entes subnacionais. Nas últimas décadas o processo de expansão acelerada da globalização resultou na descentralização do Estado, o que reverberou na autonomia de unidades subnacionais que atuam em espaços regionais. Caso exemplifica uma ação regional paradiplomática em que vários entes subancionais se unem por meio de um grupo regional integrado é a Zona de Integração do Centro-Oeste Sul-Americano (ZICOSUL). A iniciativa tem como objetivo o compartilhamento de desafios e trocas experiências para um bem comum de todos os povos que estão envolvidos, seja em âmbito público ou privado.

Neste sentido, a ZICOSUL consiste em um projeto de integração que tem como antecedentes imediatos as iniciativas do setor privado coordenadas com o setor público. A primeira reunião de seus membros ocorreu em abril de 1997, data do I Encontro da ZICOSUL, ocorrido em Antofagasta, Chile. O encontro teve como objetivo básico promover ações conjuntas tanto com os governos nacionais, quanto com os regionais por meio da participação dos entes subnacionais. A ideia era lograr uma inserção da sub-região no contexto internacional de forma competitiva, por meio de articulação, tendo como meta o desenvolvimento socioeconômico das entidades participantes.

Os membros que constituem a ZICOSUL são: províncias do norte da Argentina; departamentos do sul da Bolívia; regiões norte do Chile; todo o Paraguai; departamentos sul do Peru; todo o Uruguai; e os estados brasileiros de: Mato Grosso, Mato Grosso do Sul, Paraná, Rio Grande do Sul e Santa Catarina.

Tendo em vista a diminuta difusão e o pouco conhecimento a cerca do tema o presente trabalho abordará detalhes acerca da ZICOSUL, relacionando a iniciativa com as estratégias de integração sul-americana e as perspectivas de desenvolvimento regional, com enfoque em sua faixa de fronteira. Inicialmente o trabalho abordará o desenvolvimento regional em meio à integração sul-americana. O recorte espacial contemplará à América do Sul, num período que se inicia logo após a Segunda Guerra Mundial e vai até os dias de hoje. Serão analisadas as principais iniciativas de integração na América Latina. Neste contexto, a pesquisa abrangerá ainda o estado de Mato Grosso do Sul, criado em 1977, e suas iniciativas no âmbito da paradiplomacia, ocorridas em meio às mudanças promovidas pela globalização, que deram maior liberdade de atuação aos governos subnacionais.

$\mathrm{Na}$ sequência, o trabalho analisará os três arcos de fronteira estabelecidos pelo governo brasileiro, com destaque para o chamado Arco Central, cuja economia desponta no cenário nacional em função do setor agropecuário, apesar de desafios que persistem em áreas como educação e segurança.

Por fim, o artigo abordará a ZICOSUL, sua criação, seu papel e importância para seus membros. Para tanto foi produzido um mapa pelos autores que apresenta os entes subnacionais participantes. Também serão trabalhados por meio de tabela, os índices de IDH e de GINI das entidades que compõem a iniciativa. Será demonstrada também a evolução da ZICOSUL como instituição, entre os membros, apontando os eixos temáticos que são 
desenvolvidos, enfocando a importância do mercado asiático, em especial da China, também serão apresentados os obstáculos relacionados às dificuldades de aproximação entre os membros da ZICOSUL e a diminuição de assimetrias.

O foco da pesquisa em questão tem como intuito a análise do funcionamento da ZICOSUL em localidades em zonas de fronteira que se encontram em condições desfavoráveis economicamente, cujas áreas são primordiais quanto à integração regional. Trata-se de uma pesquisa qualitativa, básica, de cunho exploratório, sob a ótica das Relações Internacionais, do Desenvolvimento Regional e do Direito, pautada em análise bibliográfica e documental, com recorte temporal correspondente ao período entre 1997 e 2019.

\section{O desenvolvimento regional em meio à integração sul-americana}

O desenvolvimento regional tem como escopo a transformação por meio de um processo que causa uma forte ação de progresso para determinada localidade. Tudo isto através de melhoramentos focados na dignidade da vida humana, garantindo mais oportunidades de trabalho e a capacitação profissional (por meio de cursos técnicos, universitários), com o foco na qualificação para o mercado de trabalho. Além disso, também deve ser garantido o tempo para lazer, bem como um ambiente saudável que resulte no bemestar de todos, e nunca se esquecendo do meio ambiente.

O tema do desenvolvimento regional da América do Sul tem como marco temporal o período pós-Segunda Guerra Mundial, quando da criação da ONU (Organização das Nações Unidas), em 1945, e logo em seguida, em 1948, da CEPAL (Comissão Econômica para a América Latina), que buscava o incentivo e a cooperação econômica entre aqueles países que faziam parte do grupo.

A partir da década de 1970 tiveram início algumas ações de integração sub-regional na América do Sul, como, por exemplo, o Tratado de Cooperação Amazônica, que tinha o objetivo de fomentar o desenvolvimento econômico regional dos países membros. Em seguida, na década de 1980 foi fundada a ALADI (Associação Latino-Americana de Integração), criada para substituir a ALALC, e cujo objetivo era a promoção da integração e também do desenvolvimento econômico e social da região.

Já no início da década de 1990 surgiu um novo bloco regional: o MERCOSUL (Mercado Comum do Sul). O bloco abarcava países do cone sul do subcontinente sulamericano, cujos fundadores eram: Brasil, Argentina, Paraguai e Uruguai.

Todas estas iniciativas de integração (ainda que nem todas tenham obtido sucesso) tiveram como objetivo principal a promoção de projetos de desenvolvimento econômico que enfatizavam as regiões mais dinâmicas de cada país. Nesse sentido, algumas áreas periféricas e semi-periféricas não foram contempladas a contento - caso do estado brasileiro de Mato do Grosso do Sul.

Cabe ressaltar que o estado de Mato Grosso do Sul é o ente federado recente, tendo sido criado no ano de 1977, com o desmembramento do estado de Mato Grosso. Com sua criação teve início a busca por um desenvolvimento pujante, e assim tiveram continuidade alguns programas de desenvolvimento regional, cuja origem remontava a década de 1940. Nesse sentido, Dallabrida (2013, p. 115-116) recorda que:

Referimos-nos ao fato de que o que denominamos desenvolvimento regional, trata-se de um processo de mudança capaz de engendrar o dinamismo que habita um determinado território ou região. Naquilo que chamamos de melhoria das condições de vida da população, inclui-se a melhoria da renda e do poder aquisitivo da população, a inserção de mais 
trabalhadores no mercado de trabalho, a melhoria das condições salariais e de trabalho, o aumento das oportunidades de acesso à sua capacitação com cursos técnicos ou universitários, a melhoria das condições de habitabilidade, lazer, saúde, ambiente limpo e não contaminado, dentre outros fatores.

No que tange ao estado de Mato Grosso do Sul, onde a agropecuária é bastante desenvolvida, também merecem destaque dois outros setores: o da indústria e o de serviços. Setores estes que vêm sendo ajustados pelo novo paradigma tecnológico, que ocasiona em "um processo de desconcentração espacial da atividade econômica" (FORCHEZATTO, 2010).

Para tanto, se faz necessário compreender o processo de globalização ${ }^{5}$ econômica, que resulta em questionamentos acerca da soberania do Estado nacional. A partir do final do século XX o regionalismo aberto resultou em um mundo composto por blocos regionais de países. Nesse contexto, os governos subnacionais passaram a atingir determinada importância nas relações internacionais, sobretudo em iniciativas voltadas ao desenvolvimento e à integração regional.

Com as grandes mudanças após a duas grandes guerras mundiais e especificamente na década de 1970 houveram novas ações nas interrelações entre os Estados. O desastre causado por tanta intolerância e nacionalismos exacerbados reverberou na necessidade em se buscar uma atuação baseada em cooperação entre os povos e nações. Dentro deste diapasão surgiu a teoria da interdependência complexa, que foi desenvolvida por dois grandes teóricos das Relações Internacionais, a saber: Robert Keohane e Joseph Nye, os quais apontavam o conceito como:

[...], interdependência, em política mundial, refere-se a situações caracterizadas por efeitos recíprocos entre os países ou entre atores em diferentes países (KEOHANE; NYE, 1989, p. 8).

Por sua vez, Nye Jr explica a interdependência da seguinte maneira:

[...], situações nas quais os protagonistas ou os acontecimentos em diferentes partes de um sistema afetam-se mutuamente (NYE JR., 2009, p. 250-251).

Desta forma, cabe ressaltar que a integração regional tem cunho político e que perpassa pela política econômica, sendo diferenciada de propósitos exclusivamente de anseios financeiros e econômicos advindos dos desdobramentos da globalização (CORRAL, 2009).

Assim, o que vem a ser chamado de paradiplomacia como um novo fenômeno, o qual faz com que entes subnacionais se movam de forma autônoma dentro das Relações Internacionais, é explicado por Vigevani:

[...] para se entender, em parte, a emergência destes novos processos de integração e a atuação externa das unidades subnacionais, é preciso vinculálos com as mudanças ocorridas no sistema internacional, em meio ao processo de globalização econômica. A tendência de formação de blocos

\footnotetext{
${ }^{5}$ A globalização econômica, denominação atribuída ao atual momento do capitalismo, que teve início por volta do último quartel do século XX, pode ser entendida como a ocorrência simultânea de três processos: crescimento extraordinário dos fluxos internacionais de produtos e capital, acirramento da concorrência internacional e maior interdependência entre empresas e economias nacionais (GONÇALVES, 2002).
} 
regionais, a crescente transnacionalização e interdependência têm implicado vários canais de vinculação de atores diversos, ampliando os temas de tipo recíproco. (VIGEVANI, 2006, p. 132).

Fica claro que a ação destes governos subnacionais, sejam estaduais ou municipais têm papel preponderante nas relações exteriores. Isto, ainda que de forma autônoma e não independente. Há que se deixar cristalino que existe esta possibilidade a ponto de se promover a expansão das negociações internacionais com intuito de favorecer o desenvolvimento regional de forma mais eficaz.

Na década de 1990 a integração regional teve seu apogeu. Aquele foi um período em que aconteceram mudanças significativas quanto à forma de gerir dos Estados nacionais. Não obstante, estes, no presente vêm diminuindo a aptidão de atuar como sujeitos que favorecem o desenvolvimento nacional, bem como o regional. Nesse contexto Arend, Cario e Enderle (2012, p. 120) destacam a importância das inovações tecnológicas:

A direção, o ritmo, a seleção, aprendizado e a imitação das inovações remetem ao conceito de paradigma tecnológico. Segundo Dosi (1988a), um paradigma tecnológico define contextualmente as necessidades a serem atendidas, os princípios científicos a serem usados para as tarefas, a tecnologia de materiais a ser empregada (...) [portanto, um paradigma tecnológico é] um padrão de solução de problemas tecno-econômicos selecionados, baseado em princípios altamente seletivos, derivados das ciências naturais, juntamente com regras específicas direcionadas para a aquisição de novos conhecimentos e sua salvaguarda, sempre que possível, contra a rápida difusão entre seus competidores.

Neste diapasão, para ocorrer uma promoção de ambientes inovadores deve-se ter como foco a ampliação, bem como a consolidação de parques e polos tecnológicos regionais, por meio de leis e programas que visam estimular a inovação, e também incentivos financeiros, fiscais para que empresas e indústrias possam se instalar. Forchezatto (2010) recorda que "essas políticas públicas são fundamentais para colocar a região na escada do desenvolvimento".

O crescimento econômico diz respeito ao aumento da produção, e já o desenvolvimento econômico remete à elevação no nível de vida de determinada população. Com isso, em uma "visão institucionalista e neo-shumpeteriana, deve-se considerar os aspectos históricos, políticos, sociais e econômicos num processo evolucionário" (AREND; CARIO; ENDERLE, 2012, p. 125). Nesse sentido o presente estudo pretende se basear no entendimento específico do desenvolvimento econômico regional no âmbito internacional supracitado para analisar a atuação de Mato Grosso do Sul na ZICOSUL.

\section{Faixa de fronteira do Brasil: desafios ao desenvolvimento regional}

O antigo Ministério de Integração Nacional (que em 01 de janeiro de 2019 foi fundido com o Ministério das Cidades dando origem ao Ministério do Desenvolvimento Regional) classificava as diferentes partes da faixa de fronteira do Brasil em uma regionalização que estabelecia três arcos: Sul, Central e Norte. Em tal regionalização, os municípios sul-matogrossenses localizados no Arco Central têm como potencialidade de desenvolvimento arranjos produtivos locais ligados a: agropecuária, construção civil, mineração, madeira e turismo (BRASIL, 2009). 
O Arco Central é caracterizado por configurar uma área de transição entre a Amazônia e o Centro-Sul do país. Este arco abrange duas grandes bacias hidrográficas sulamericanas, a Bacia Amazônica e a Bacia do Paraná- Paraguai. A economia dos municípios do Arco Central, em especial os da faixa de fronteira de Mato Grosso do Sul, abarca atividades como: a) ecoturismo, que atrai milhares de pessoas e tem um papel importante no desenvolvimento da economia regional; b) pecuária, visto que há um grande rebanho bovino se espalha pela faixa de fronteira, sendo o Mato Grosso do Sul o terceiro maior produtor do país, com 10,19\% do rebanho nacional, ficando atrás apenas dos estados de Goiás e Mato Grosso (IBGE, 2019); c) soja, cujo alargamento da produção de forma mecanizada esbarra em gargalos de escoamento.

Embora o turismo, a pecuária e a soja sejam os carros chefes da economia dos municípios sul-mato-grossenses do Arco Central existem outros arranjos produtivos locais com potencial de desenvolvimento. Nesse sentido, cabe destacar a expansão da fruticultura (limão, laranja, manga, caju e banana); bem como as chamadas lavouras esporádicas, que são a de mandioca, arroz e também a de cana-de-açúcar.

A faixa de fronteira de Mato Grosso do Sul é caracterizada pela economia pouco diversificada e pela dependência em relação a alguns setores. Por exemplo, na região de Porto Murtinho, onde há extração de madeira e baixa diversificação da produção o turismo é o setor que mais emprega. Há também uma cadeia produtiva basilar para a agroindústria tanto de mandioca, como de soja provenientes do Paraguai (BRASIL, 2009).

No que tange à segurança pública a faixa de fronteira do Brasil possui, de acordo com o Ministério da Justiça uma série de pontos vulneráveis ao longo dos três arcos. O Arco Central possui sete áreas identificadas pelo Ministério, sendo três dessas localizadas no estado de Mato Grosso do Sul. A saber: BR-262 - saída de Corumbá para Campo Grande; área do Pantanal sul-mato-grossense na fronteira com a Bolívia, Região de Amambai; e a fronteira seca de Mato Grosso do Sul com o Paraguai, entre as cidades de Antônio João e Mundo Novo (IPEA, 2016).

A faixa de fronteira de Mato Grosso do Sul é caracterizada, assim como outras partes da faixa de fronteira do Brasil, por baixos índices de educação, capital humano, trabalho e renda. Situação materializada nas sete cidades gêmeas do estado (Bela Vista, Coronel Sapucaia, Corumbá, Mundo Novo, Paranhos, Ponta Porã e Porto Murtinho), que possuem um PIB per capita inferior à média nacional (tabela 1). Municípios como Paranhos e Coronel Sapucaia possuem taxas elevadas de evasão escolar. Quanto menor a escolaridade consequentemente menores são as oportunidades de emprego e renda, bem como de conhecimento sobre cuidados com a saúde. Estes fatores explicam os altos índices de violência e mortalidade infantil, que superam a média nacional (IDESF, 2018).

Tabela 1: Cidades gêmeas de Mato Grosso do Sul: População e PIB

\begin{tabular}{|c|c|c|}
\hline Municípios & População estimada (2019) & PIB (2016) \\
\hline Bela Vista & 24.629 & $17.344,46$ \\
\hline Coronel Sapucaia & 15.253 & $11.957,95$ \\
\hline Corumbá & 111.435 & $25.154,17$ \\
\hline Mundo Novo & 18.366 & $21.490,10$ \\
\hline Paranhos & 14.228 & $10.768,86$ \\
\hline Ponta Porã & 92.526 & $26.003,90$ \\
\hline Porto Murtinho & 17.131 & $17.662,04$ \\
\hline
\end{tabular}


EM

QUESTÃO
\begin{tabular}{|c|c|c|}
\hline Média Nacional & - & pág. 52-64 \\
\hline
\end{tabular}

Fonte: IBGE, 2019. Organizado pelos autores, 2019.

A tabela 1 demonstra que as cidades de Corumbá e Ponta Porã são as maiores e consequentemente as mais importantes cidades gêmeas de Mato Grosso do Sul tendo uma população muito superior e possuindo um PIB maior do que as demais.

\section{ZICOSUL: paradiplomacia na América do Sul}

A ZICOSUL, composta por unidades subnacionais de sete países sul-americanos constitui uma iniciativa público-privada pouco conhecida e difundida na mídia brasileira. A iniciativa possui grande potencial de alavancar o desenvolvimento regional.

A ZICOSUL está inserida em um âmbito no qual seus participantes (mapa 1) são os entes subnacionais (estados, províncias e departamentos), os quais têm suas ações manifestas em foros voltados às negociações internacionais. Isto se dá a partir de ações de descentralização do poder do Estado, mais autonomia aos governos subnacionais, que podem então amplificar suas vozes, em especial no que tange à cooperação econômica, bem como a segurança, entre outros temas (MOTT; GUANAES, 2017).

Hoje, a ZICOSUL está constituída em um âmbito muito privilegiado para o exercício da paradiplomacia por meio de um marco inter-regional América Latina/Ásia. A tabela 2 apresenta os índices de GINI e o IDH dos países que possuem entes participantes da ZICOSUL. Fica bastante destacada a desigualdade social, que é um desafio a mais para a contemplação dos objetivos da ZICOSUL e suas propostas em desenvolver a integração por meio da cooperação internacional.

Tabela 2: Ranking de países por IDH e índice de GINI

\begin{tabular}{|l|c|c|}
\hline \multicolumn{1}{|c|}{ País } & IDH & Índice de GINI \\
\hline Argentina & 0.825 & 50,0 \\
\hline Brasil & 0.759 & 55,0 \\
\hline Paraguai & 0.702 & 53,2 \\
\hline Uruguai & 0.804 & 46,2 \\
\hline Chile & 0.843 & 52,1 \\
\hline Bolívia & 0.693 & 58,2 \\
\hline Peru & 0.750 & 52,0 \\
\hline
\end{tabular}

Fonte: Atlas Brasil (2020).

A ZICOSUL foi contemplada na OEA (Organização dos Estados Americanos) com a assinatura de um documento histórico, que garantiu aos 70 entes subnacionais participantes do organismo internacional a concessão de institucionalidade e também a condição de sujeitos de cooperação de pleno direito, pela qual os membros desenvolvem uma integração nos âmbitos comercial, financeiro, educacional, científico-tecnológico, cultural e social da região do Centro-Oeste da América do Sul. 
Mapa 1: Entidades membros da ZICOSUL

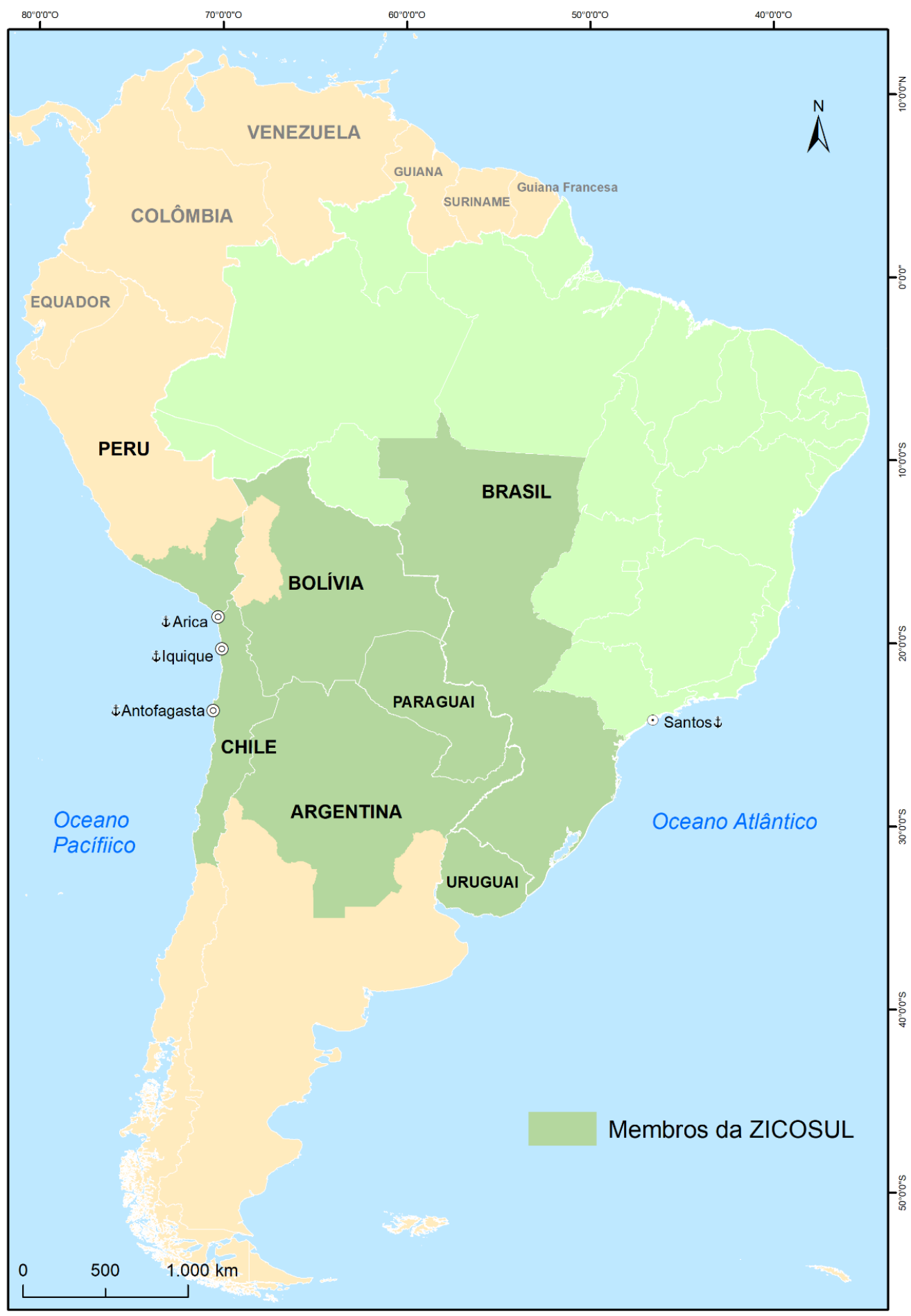

Fonte: Elaborado pelos autores (2020).

Os países da América do Sul, a partir do fim da Guerra Fria permitiu que puderam repensar suas relações inter-regionais e assim redesenhar os projetos de integração. Assim como a Europa, os governos locais, por meio de iniciativas como a ZICOSUL, puderam desenvolver ações de internacionalização até então inéditas. A nova conjuntura proporcionou ferramentas necessárias para a inserção de entes subnacionais na nova ordem mundial. Uma 
condição favorável que antes inexistia em função do centralismo político e econômico estagnado desde a formação dos Estados nacionais (SAFAROV, 2019).

Nesse sentido, a ZICOSUL propõem alguns temas específicos relacionados em quatro áreas específicas, a saber: 1) Comércio e Indústria, tendo por meta coordenar os esforços produtivos, seja de transporte e até mesmo a distribuição para alavancar a capacidade de produzir do Norte Argentino, Paraguai, Sul da Bolívia, Brasil e Chile, em especial por meio do Corredor Bioceânico, tendo como destino os portos das regiões do Chile que escoarão mercadorias aos países do Pacífico e da Ásia; 2) Infraestrutura e Serviços, com enfoque na interconexão das hidrovias Paraguai-Paraná e Paraná-Tietê, e no desenvolvimento de transportes multimodais e potencialização do ferroviário por meio da utilização do Corredor Bioceânico Norte-Pacífico-Atlântico, logrando a progressiva integração energética, em especial de complexos energéticos e de gás da região Bolívia-Argentina-Brasil, buscando uma maior desburocratização no controle fronteiriço dos países que fazem parte da sub-região; 3) Meio Ambiente, que tem como escopo a promoção do desenvolvimento sustentável por meio de uma legislação ambiental que se aplique aos membros da ZICOSUL; 4) Turismo e Cultura, que enfoca a inserção e integração turística entre as regiões membros da ZICOSUL, com intuito de facilitar a entrada e saída nos postos aduaneiros, bem como nas rodovias, agilizando um maior conhecimento geográfico, político, histórico e social da região.

Configurando uma prioridade pelos membros que a compõem, a ZICOSUL tem como foco especial o mercado asiático. Contudo, houve um grande avanço quanto a à integração dos atores subnacionais, que possuem o objetivo de criar um cinturão, um caminho visando unir as costas do Atlântico e do Pacífico da América do Sul. Ainda que na Declaração de Assunção no ano de 2015 nada tenha se projetado para a ZICOSUL pelos governos de Argentina, Brasil, Chile e Paraguai quanto ao Corredor Bioceânico que atravessará Porto Murtinho-MS, ainda assim existirão grandes benefícios para os entes participantes caso os objetivos principais da iniciativa sejam concretizados.

Há que se ressaltar que ocorreram encontros ZICOSUL-Asía do Pacífico na cidade de Antofagasta, Chile, no ano de 2014, e depois em 2015, quando aconteceram reuniões diplomáticas envolvendo alguns países asiáticos, bem como membros do Fórum de Cooperação Econômica da Ásia-Pacífico (APEC). Nestas reuniões todos os membros da ZICOSUL foram representados.

Por existir forte demanda do empresariado do Brasil em aumentar seus negócios com a Ásia, houve grande interesse em apoiar o projeto do Corredor Bioceânico que atravessa o Paraguai, o norte da Argentina e termina no norte do Chile, tendo em vista que os portos do Atlântico não mais satisfazem a contento o escoamento de mercadorias para Ásia (CORTEZ; PIZARRO, 2018).

A ZICOSUL configura um tipo de diplomacia descentralizada que conta com a participação de regiões peruanas e chilenas que têm melhor localização geográfica portuária (Pacífico) em comparação ao litoral atlântico, onde ficam os portos dos países que compõem o MERCOSUL, os quais têm interesse em comercializar com os portos asiáticos. Desta forma, o objetivo principal é promover um desenvolvimento econômico para atingir a região do Pacífico asiático por meio de uma ação paradiplomática dos entes subnacionais que formam a ZICOSUL. Sobretudo em um intercâmbio pujante com a China, a qual não tem relações formais com este grupo.

Contudo, por meios informais é possível, gradativamente, formalizar relações com a China, visando, a longo prazo, uma completa institucionalização. Isto porque os chineses têm muito interesse na sub-região que proporciona os recursos naturais renováveis e não renováveis, além de abrigarem vastas terras agricultáveis e uma ampla e vasta lista de insumos que muito são úteis para a indústria chinesa. 
A cooperação entre a ZICOSUL e a China teve seu início por meio do modelo de coexistência do Estado e dos governos subnacionais, de curto a médio prazo, isto porque a industrialização incipiente dos países sul-americanos gerou o dilema do interesse chinês quanto aos recursos existentes na América do Sul (OVIEDO, 2011).

O número elevado de habitantes em território chinês tem consumido uma grande parte dos recursos de seu território. Assim, há a busca por outras regiões capazes de produzir matérias primas necessárias e o estabelecimento de canais de acesso aos recursos. Isto configuraria um contexto de interação assimétrica de poder, no estilo Norte-Sul, onde através do comércio exterior, os países sul-americanos exportariam matérias primas e a China exportaria produtos industrializados (OVIEDO, 2011).

No ano de 2002 a Secretaria de Relações Internacionais e Comércio Exterior da Província do Chaco, que ocupava a Secretaria Pro-tempore da V Reunião ZICOSUL/2002 elaborou o documento ZICOSUL, o qual definiu o projeto como a Zona de Integração do Centro-Oeste da América do Sul com intuito de somar esforços para o desenvolvimento do comércio exterior com o mercado do Pacífico. Nos anos seguintes, a ZICOSUL flexibilizou seu objetivo principal que se transformou na seguinte meta: conseguir a inserção da subregião no contexto internacional buscando a competitividade, desenvolvendo o comércio exterior com mercados internacionais por meio de articulações de eixos de comunicação, buscando também a promoção da integração social e cultural com foco no desenvolvimento econômico-social das regiões envolvidas.

Não obstante existe um ponto bastante delicado, porém muito importante para a ZICOSUL que são as relações bilaterais conflitivas quanto à definição de limites fronteiriços, disputas originários da Guerra do Pacífico (1879-1883), cujas demandas chegaram à Corte Internacional de Haia.

Desta forma a estrutura institucional contempla encontros regulares com um comitê de governadores, prefeitos e outras autoridades regionais da ZICOSUL que buscam uma condução para o avanço na relação com a Ásia-Pacífico, criando organizações e encontros que promovam a atividade paradiplomática das unidades subnacionais da região. Nesse sentido, a região escolhida para sediar o primeiro encontro foi a região chilena de Tarapacá, que integra a ZICOSUL e compõe uma tríplice fronteira entre Chile, Bolívia e Peru. Uma região problemática, com um passado de guerra, que testemunha na atualidade migrações de cunho laboral e a ocorrência de manifestações xenofóbicas (CLEMENTE, 2018).

Em 2019 ocorreu o $1^{\circ}$ Simpósio Internacional ZICOSUL ${ }^{6}$ Universitário no estado do Paraná, cujo tema foi o desenvolvimento sustentável. Juntamente com o simpósio aconteceram a $29^{a}$ Plenária de Reitores da Rede ZICOSUL Universitário e o $4^{\circ}$ Encontro de Relações Internacionais ZICOSUL Universitário (PARANÁ, 2019).

A rede ZICOSUL universitária teve seu início na Argentina no ano de 2005 tendo como meta o fortalecimento da integração regional por meio de intercâmbios no âmbito da educação (ensino, pesquisa e extensão), visando impulsionar e alicerçar pontos temáticos ligados à docência em prol do desenvolvimento da integração regional na esfera da cooperação acadêmica.

Isto demonstra a importância desta instituição no tocante à integração dos entes membros, e em especial por meio dos governos locais, bem como das universidades públicas

\footnotetext{
${ }^{6} \mathrm{O}$ evento foi organizado pela Rede ZICOSUL e pela Universidade Estadual do Paraná (Unespar) em parceria com a Secretaria da Ciência, Tecnologia e Ensino Superior (Seti), Centro Universitário de Estudos e Pesquisas sobre Desastres do Paraná (CEPED), Fundação Araucária, Parque Tecnológico de Itaipu, Universidade Estadual do Centro-Oeste (Unicentro), Universidad Nacional de Salta e o Consulado Argentino em Curitiba.
} 
imbuídas em atender tratativas da ONU que visam o desenvolvimento do milênio, a erradicação da pobreza e efetiva integração em âmbitos sócio-econômico e ambiental para um desenvolvimento sustentável.

\section{Considerações finais}

Os projetos governamentais voltados para o desenvolvimento dos entes subnacionais e das zonas de fronteira da ZICOSUL devem levar em consideração as potencialidades locais e os arranjos produtivos. Muitos dos quais, no caso brasileiro, já identificados pelo antigo Ministério da Integração Nacional. A saber: turismo e agropecuária. Em escala transnacional esta estratégia também pode ser usada nos projetos de desenvolvimento nos demais membros da ZICOSUL.

Não obstante, a busca por ações eficazes dentro da paradiplomacia por meio dos entes subnacionais tem muito de sua dependência nos agentes políticos que estão no poder, contudo com a informação por meio das universidades, das organizações civis, e movimentos sociais é possível dar início a uma cultura de conhecimento através de fóruns, simpósios, encontros internacionais, demonstrando quão assertivo é a cooperação entre os membros da ZICOSUL.

Como elemento fundamental de qualquer política, a análise do ambiente é parte integrante nos projetos de desenvolvimento, sendo o conhecimento das peculiaridades locais bem como as possíveis influencias dos países vizinhos, nas regiões de fronteira, estratégias de internacionalização abrangentes que englobam tanto os produtores de commodities, quanto os arranjos produtivos locais.

A inserção internacional dos entes sub-regionais, bem como o êxito dos projetos de desenvolvimento no âmbito da ZICOSUL dependem de uma integração mais eficiente (em prol do desenvolvimento regional) por parte de municípios, sociedade civil e universidades. Para tanto, é necessária uma política de Estado que não dependa da alternância de poder no governo.

No Brasil, estados fronteiriços, como o Mato Grosso do Sul, constituem espaços de oportunidades, especialmente no que tange a países vizinhos como Bolívia e Paraguai. No âmbito da cooperação internacional, em especial no ambiente das zonas de fronteira da ZICOSUL, há grande potencial para que governos locais desenvolvam iniciativas de desenvolvimento de forma autônoma, sem depender exclusivamente de outras esferas estatais.

$\mathrm{O}$ presente artigo trouxe à baila um tema pouco difundido pela mídia e pelos círculos acadêmicos, no intuito de esclarecer a população interessada em fazer parte deste processo de integração regional, por meio de trocas de experiências, conhecimentos mútuos, negociações, etc. Por fim, a grande contribuição da ZICOSUL poderá se dar no fomento da infraestrutura de ligação entre as regiões litorâneas da América do Sul, por meio do Corredor Bioceânico, bem como no fomento da educação, com a promoção de intercâmbios de pesquisa e ensino.

\section{REFERÊNCIAS}

ARANDA, Gilberto; OVANDO, Christian; CORDER, Alejandro. Experiencias paradiplomáticas en la región de Tarapacá y su proyección sub-regional. In: Estudios Internacionales, n. 165, p. 33-74. 2010.

AREND, Marcelo; CARIO, Silvio Antonio Ferraz; ENDERLE, Rogério A. Instituições, inovações e desenvolvimento econômico. Revista Pesquisa e Debate, SP, vol. 23, n. 1, p.110-133, 2012. 
EM

QUESTÃO

V.13 N. $02 \downarrow 2020$

pág. 52-64

ATLAS BRASIL. Atlas do Desenvolvimento Humano no Brasil. Disponível em: http://www.atlasbrasil.org.br/2013/pt. Acesso em: 28 jan. 2020.

CLEMENTE, Isabel. Paradiplomacia e relações transfronteiriças. Civitas - Revista de Ciências Sociais. vol.18 no.2 Porto Alegre May/Aug. 2018.

CORRAL, Amalia del Carmen Casas de las Peñas del. A integração energética na América do Sul: instrumentos jurídicos e institucionais para projetos gasíferos regionais. Tese (Doutorado). Programa de Pós-Graduação em Direito da Universidade Estadual do Rio de Janeiro. Rio de Janeiro: UERJ, 2009, 357p.

DALLABRIDA, Valdir Roque. Desenvolvimento regional na região ou território do Contestado: algumas reflexões a partir da análise da sua matriz produtiva. In: Dallabrida, Valdir Roque. Território, identidade territorial e desenvolvimento regional: reflexões sobre indicação geográfica e novas possibilidades de desenvolvimento com base em ativos com especificidade territorial. São Paulo: Liberars, 2013. Cap. 5. p. 111-126.

FOCHEZATTO; Adelar. Desenvolvimento Regional: Novas abordagens para novos paradigmas produtivos. Revista Ambiente Regional, v. 1, p.160-192; 2010.

GHADIE, Aida. A inserção internacional das cidades médias na faixa de fronteira: o caso da cidade de Dourados. Dissertação (Mestrado). PPGFDH. Dourados: UFGD, 2019. 145 p. Disponível em: http://repositorio.ufgd.edu.br/jspui/bitstream/prefix/1085/1/AidaMohamedGhadie.pdf. Acesso em: 11 nov. 2019.

GONÇALVES, Reinaldo, O Nó Econômico. Rio de Janeiro: Editora Record, 2002.

IBGE.Cidades@.Disponível em: https://cidades.ibge.gov.br/. Acesso em: 11 nov. 2019.

IDESF. Diagnóstico do desenvolvimento das cidades gêmeas do Brasil. Educação, saúde, economia e segurança pública: a análise dos números. Foz do Iguaçu: Editora IDESF, 2018.

IPEA. Fronteiras do Brasil: uma avaliação do arco Norte. Boa Vista: IPEA, 2016.

KEOHANE, Robert O. \& NYE, Joseph S. Power and interdependence. 26a ed. Nova York: Harper Collins, 1989.

MOTT, Macarena Mercado; GUANAES, Senilde Alcântara. IIRSA y ZICOSUR en el Norte Argentino: ¿Infraestructura para la integración o integración para la infraestructura?. Hegemonia - Revista Eletrônica de Relações Internacionais do Centro Universitário Unieuro, Brasília, número 20, jan.-jun. 2017, p. 89-119.

NYE JR., Joseph S. Cooperação e conflito nas relações internacionais. São Paulo: Editora Gente, 2009, p. 250-251.

OVIEDO, Eduardo Daniel. La proyección de la ZICOSUR en el mundo: el horizonte de cooperación y rivalidade económica con China. In: Anales del I Simposio Electrónico Internacional sobre Política China. Madri: Observatorio de la Política China España, 2011. 
PARANÁ. Rede Zicosur debate desenvolvimento sustentável em $\mathbf{1}^{\circ}$ Simpósio Internacional, 07/05/2019. Disponível em: http://www.seti.pr.gov.br/Noticia/Rede-Zicosurdebate-desenvolvimento-sustentavel-em-1o-Simposio-Internacional. Acesso em: 18 dez. 2019.

SAFAROV, Alejandro. La Paradiplomacia del Noroeste Argentino: El caso ZICOSUR. Revista de la Secretaría del Tribunal Permanente de Revisión. Ago. 2019, ano 7, nº 14, p. 283-294.

VIGEVANI, Tullo. Problemas para a atividade internacional das unidades subnacionais: estados e municípios brasileiros. Rev. Bras. Ci. Soc. V. 21, n. 62. São Paulo, out. 2006, p. 127-139.

\section{Nota biográfica:}

Fábio Roberto Cordeiro - Graduado em Relações Internacionais, discente do Mestrado em Fronteiras e Direitos Humanos da UFGD.

Alexandre Bergamin Vieria - Doutor em Geografia, Professor dos cursos de Graduação e Pós-graduação em Geografia da UFGD. Coordenador do Laboratório de Planejamento Regional (LAPLAN) da FCH/UFGD. Membro do Grupo de Pesquisa Saúde, Espaço e Fronteira(s).

Kamila Madureira da Silva - Engenheira Agrônoma, pós graduação em gestão ambiental, licenciada em Geografia, mestranda em Geografia pela Universidade da Grande Dourados. Coordenadora de Políticas Públicas para Mulheres no município de Caarapó, professora na rede Estadual de Ensino de Mato Grosso do Sul, no Avanço do Jovem na Aprendizagem e no Curso Técnico Açúcar e Álcool.

Camilo Pereira Carneiro Filho - Doutor em Geografia, Professor visitante do Mestrado em Fronteiras e Direitos Humanos da UFGD, autor do livro Fronteiras Irmãs: transfronteirizações na Bacia do Prata. Autor de dezenas de artigos científicos sobre fronteiras e integração regional. 